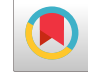

\title{
Antimicrobial Effect of Myrtus communis. L. Essential Oils Against Oral Microorganism
}

\author{
Neda Rasaie ${ }^{1}$, Elaheh Esfandiari ${ }^{2,}{ }^{*}$, Shervin Rasouli ${ }^{3}$ and Fatemeh Abdolahian ${ }^{2}$ \\ ${ }^{1}$ Department of Periodontology, School of Dental Medicine, Ahvaz Jundishapur University of Medical Sciences, Ahvaz, IR Iran \\ ${ }^{2}$ Department of Periodontology, School of Dentistry, Ahvaz Jundishapur University of Medical Sciences, Ahvaz, IR Iran \\ ${ }^{3}$ School of Dentistry, Ahvaz Jundishapur University of Medical Sciences, Ahvaz, IR Iran \\ "Corresponding author: Elaheh Esfandiari, Resident of Periodontics, Department of Periodontology, School of Dental Medicine, Ahvaz Jundishapur University of Medical \\ Sciences, Ahvaz, IR Iran. Tel: +98-9133865262, E-mail: esfandiari.elaheh@gmail.com
}

Received 2017 April 24; Accepted 2017 December 10.

\begin{abstract}
The aim of this study was to evaluate the antimicrobial effects of essential oils (EOs) isolated from Myrtus communis L. (myrtle)against Streptococcus mutants, Streptococcus sanguis, and Streptococcus salivarius through in vitro experiments. The EOs was isolated from myrtle leaves by the hydrodistillation method. The disc diffusion method was used to evaluate the zone of microbial growth inhibition by different concentrations of the EOs. The inhibition zone for all concentrations was measured in diameter (MM) after incubation at $37^{\circ}$ for 18 hours. According to these measurements, the Minimal inhibitory concentration for each bacterium was reported. Tetracycline and erythromycin were used as positive control. The result showed that EOs of myrtle leaves had antimicrobial activity on disk-diffusions plates against all strains of Streptococcus, which were tested; however, S. mutants showed greater susceptibility than others. EOs of myrtle leaves could be recommended as a potential remedy for prevention the colonization of teeth by Streptococcus mutants and hinder the development of dental caries.
\end{abstract}

Keywords: Myrtus, Streptococcus, In Vitro, Dental Caries

\section{Background}

Oral infections are the most common dental diseases caused by bacteria. Periodontal disease and dental caries are known as chronic infections (1) and they can be linked with other serious chronic problems like cardiovascular disease (2). While we try to control pathogens, multidrug resistant(MDR) strains are increasing and the limited numbers of antimicrobial agents are available for treatment of these infections (3). Except for antimicrobial resistance, side effects, high costs, and environmental problems leaded to novel antimicrobial agents or treatment strategies (4). Recently there is an increasing interest to use EOs for infections control (5). In oral medicine, EOs are used in many different ways, such as in oral hygiene, dental implants, as anxiolytic, and preservatives (6). EOs are plant's volatile secondary components and they are found particularly in plant's flowers and leaves (7). Secondary metabolisms are described as the "silent metabolism" due to their critical role in increasing plant fitness and defense (8). Until now, more than 3,000 essential oils have been described, of which about one-tenth are relevant for pharmaceutical, nutritional, or cosmetic industries. Several essential oils have a strong interest in research for their cytotoxic capacity. Great efforts are performed in order to inves- tigate the potential therapeutic effects of oils against several diseases, especially those characterized by excessive cell growth and proliferation such as cancer or bacterial infections $(9,10)$. In fact, EOs have been used for over 5,000 years as health-promoting agents for the treatment of various diseases (7). Use of EOs in traditional persian medicine (TPM) dates back prior to $637 \mathrm{AD}$. In addition, new clinical trials have highlighted specific positive effects of EOs on both the physiological and psychological of human subjects (11-15). Interestingly, some of the investigations evidenced that EOs can be useful against multidrug-resistant bacteria $(16,17)$. One of the plants that it's EOs has been investigated is Myrtus communis L. (common name: myrtle). It is an evergreen shrub belonging to the Myrtaceae family (18).

a-Pinene, limonene, 1,8-cineole, and linalool have been reported as major compounds of Persian M. communis EOs (19). Limonene was found as an inhibitor of streptococcal biofilm formation in subrameniam study (20). In addition, Mitrakul reported that Citrus EOs contain L-limonene inhibited streptococcus mutants biofilm formation (21). Antimicrobial effects of the EOs of Myrtus against several bacterial and fungal strains such as Staphylococcus aureus and Streptococcus pneumonia were also reported by Baharvand-Ahmadi et al. (22). Accordingly, the aim of this 
study was to evaluate the in vitro antimicrobial effect of myrtle essential oils against different mutants of streptococcus that cause dental plaque and gum disease.

\section{Methods}

\subsection{Plant Materials}

M. communis leaves were collected from Izeh district of Khosestan-Iran in April 2011.

\subsection{Microbial Cultures and Media}

Mueller Hinton agar (MHA) and blood agar plates (BAPs) were prepared according to the (23) method.

Streptococcus mutans (PTCC 1683), Streptococcus sanguinis (PTCC 1449), and Streptococcus salivarius (PTCC 1448) obtained from Iranian research organization for science and technology (IROST). According to the kite protocol, microbial suspensions were obtained by diluting each bacterial vial in serialized serum. The microbial suspensions were cultured on MHA media at $37^{\circ} \mathrm{C}$ for 18 hours. Microbial suspensions were then made from the agar plates using the sterile serum at a concentration of approximately $1.5 \times 10^{8}$ /mL(0.5 McFarland standards). The above suspension from each bacterium was used on BAP media (23).

\subsection{Essential Oils Extraction}

Essential oils extraction was carried out according to the method explained by Berka-Zougali et al. (24) with slight modifications. Leaves were washed and dried during 5 days. Hydrodistillation method was used. A quantity of $100 \mathrm{~g}$ of crushed leaves of myrtle was immersed in $500 \mathrm{~mL}$ of distilled water contained in a 2 L flask. Distillation was performed using a modified Clevenger's glass apparatus. The extraction process was carried out for 6 hours after the first drop of distillate until complete exhaustion of the plant. The distillation started after a heating time of 40 minutes. The condensation was carried out continuously with water chilled to $5^{\circ} \mathrm{C}$. Trials were performed with three successive repetitions. The essential oils extracted were stored in dark glass bottles in $4^{\circ} \mathrm{C}$ until it was used.

\subsection{Essential Oils Dilution}

Various solvents such as ethanol, methanol, acetone, butanol, and diethyl ether were tested for their antimicrobial activities using the disc diffusion method. Methanol was selected as a diluting medium for the EOs due to the fact that it did not show any antimicrobial activity. Therefore, methanol was used as the control and 1/2,1/4,1/8, 1/16, 1/32,1/64 dilutions of EOs were made with methanol. Undiluted oil was taken as dilution number one (100\%) (25).

\subsection{EOs Disc Preparation}

Discs were bought from Padtan teb®. A $6 \mathrm{~mm}$ disc size was used (Whatman No.1). We put disks on the sterilized plates and loaded $20 \mu \mathrm{L}$ of the EOs on each disc. Plates were put in $37^{\circ} \mathrm{C}$ for 30 minutes in order to evaporate the solvent.

\subsection{Antimicrobial Analysis}

The fresh oil we used was for its antimicrobial activities. Disc diffusion method was used. According to the method, sterile Mueller- Hinton agar and blood- agar medium was used for the antimicrobials assay of. S. Mutants, S. salivaris, and S. Sanguis.

The media in plates were allowed to solidify and then the microbial suspension was streak over the surface of the medium using a sterile cotton swab and under the aseptic conditions the EOs discs were placed on agar plates.

The plates were then incubated for 18 hours at $37^{\circ} \mathrm{C}$ in order to get reliable microbial growth. Microbial inhibition zone were measured using a ruler by millimeters (26). The mean of triplicate experiments of each treatment was determined and antibiotic and methanol were used as controls.

\subsection{MIC Determination of the EOS}

The minimal inhibitory concentration (MIC) was determined by the Etest method. Three different Bacterial suspensions in 0.5 McFarland concentration were spread on MHA petri dishes media. Eight discs of EOs from highest to the lowest concentration were put on the line on the surface of BAP media. Pure methanol disc was added as a control. Petri dishes were incubated for 18 hours at $37^{\circ} \mathrm{C}$ in order to get reliable microbial growth (23).

\subsection{Statistical Analysis}

Data were analyzed by SPSS version 16 . ANOVA was used for comparing treatment groups means at $\mathrm{P} \leq 0.01$ in three replications.

\section{Results and Discussion}

Bacterial growth inhibition was noted for all streptococcus varieties in Tables 1 - 3. Inhibitory effect of all concentrations of EOs were evaluated by the positive control, which was antibiotic. The result showed that in some concentrations of EOs there weren't any significant changes compared to the commercial antibiotics. In Table 1, the EOs from M. communis inhibited S. mutans growth the same as tetracycline $30 \mu \mathrm{g}$, in $100 \%, 50 \%, 25 \%$, and $12.5 \%$ of concentrations.

In the case of S. salivaris, inhibition zone of EOs 100\% and tetracycline $30 \mu \mathrm{g}$ were the same. Inhibition zone of 


\begin{tabular}{|c|c|c|c|c|}
\hline Oil Dilutions, \% & Rep1, mm & Rep2, mm & Rep3, mm & Mean, $\mathbf{m m}$ \\
\hline 100 & 31 & $29 / 2$ & 30 & $30.5^{\mathrm{a}}$ \\
\hline 50 & 25 & 26 & 25 & $25.3^{\mathrm{a}}$ \\
\hline 25 & $21 / 5$ & 22 & 21 & $21 / 5^{\mathrm{a}}$ \\
\hline 12.5 & $18 / 6$ & $18 / 5$ & 18 & $18^{\mathrm{a}}$ \\
\hline 3.125 & 11 & 11 & 10 & $10.7^{\mathrm{b}}$ \\
\hline 1.562 & 0 & 0 & 0 & $0^{\mathrm{b}}$ \\
\hline \multicolumn{5}{|l|}{ Control } \\
\hline Tetracycline $30 \mu \mathrm{g} /$ disc & 21 & 19 & 22 & 20.7 \\
\hline Methanol & 0 & 0 & 0 & 0 \\
\hline
\end{tabular}

${ }^{a}$ Non significant change compare to tetracycline.

${ }^{\mathrm{b}}$ Significant decrease compare to tetracycline.

\begin{tabular}{|c|c|c|c|c|}
\hline EOs Dilutions, \% & Rep1, mm & Rep2, mm & Rep3, mm & Mean, mm \\
\hline 100 & 23 & 23 & 23.5 & $23.2^{\mathrm{a}}$ \\
\hline 50 & 17 & 17 & 18.4 & $17.5^{\mathrm{b}}$ \\
\hline 25 & 15 & 14 & 15 & $14.7^{\mathrm{b}}$ \\
\hline 12.5 & 12 & 11 & 12 & $11.7^{\mathrm{b}}$ \\
\hline 6.25 & 8 & 7 & 7 & $7.3^{\mathrm{b}}$ \\
\hline 3.125 & 7 & 8 & 8 & $7.7^{\mathrm{b}}$ \\
\hline 1.562 & 0 & 0 & 0 & $0^{\mathrm{b}}$ \\
\hline \multicolumn{5}{|l|}{ Control } \\
\hline Tetracycline $30 \mu \mathrm{g} /$ disc & 26 & 26 & 26 & 26 \\
\hline Methanol & 0 & 0 & 0 & 0 \\
\hline
\end{tabular}

${ }^{\mathrm{a}}$ Non significant change compare to tetracycline.

${ }^{\mathrm{b}}$ Significant decrease compare to tetracycline.

\begin{tabular}{|c|c|c|c|c|}
\hline EOs Dilutions, \% & Rep1, mm & Rep2, mm & Rep3, mm & Mean, $\mathbf{m m}$ \\
\hline 100 & 26 & 26 & 24 & $25.3^{\mathrm{a}}$ \\
\hline 50 & 24 & 23 & 24 & $23.7^{\mathrm{a}}$ \\
\hline 25 & 20 & 21 & 20 & $20.3^{\mathrm{b}}$ \\
\hline 12.5 & 15 & 14 & 14 & $14.3^{\mathrm{b}}$ \\
\hline 6.25 & 7 & 7 & 8 & $7.3^{\mathrm{a}}$ \\
\hline 3.125 & 0 & 0 & 0 & $0^{\mathrm{a}}$ \\
\hline 1.562 & 0 & 0 & 0 & $0^{\mathrm{a}}$ \\
\hline \multicolumn{5}{|l|}{ Control } \\
\hline Erythromycin $16 \mu \mathrm{g} /$ disc & 17 & 17 & 18 & 17.3 \\
\hline Methanol & 0 & 0 & 0 & 0 \\
\hline
\end{tabular}

${ }^{a}$ Significant change compare to tetracycline.

${ }^{\mathrm{b}}$ Non significant change compare to erythromycin.

other EOs concentrations was significantly lower than the tetracycline (Table 2).

S. sanguis growth was inhibited under EOs treatment even better that erythromycin (Table 3). When we used erythromycin $16 \mu \mathrm{g}$, the bacteria inhibited area was $17.3 \mathrm{~mm}$. While by using $100 \%$ and $50 \%$ of EOs, we measured $25.3 \mathrm{~mm}$ and $23.7 \mathrm{~mm}$ of bacteria inhibited area, which was signifi- cantly more than the area that was made by using $16 \mu \mathrm{g}$ of erythromycin. The inhibitory area by $25 \%$ and $12.5 \%$ was the same as erythromycin. Lower concentrations of EOs had significantly lower inhibition than erythromycin (Table 3).

According to Tables 1 - 3, Myrtle oil has good antimicrobial activity against all three strains that were tested. Then, we determined the minimal inhibitory concentra- 
tion (MIC) of EOs by disc diffusion method.

The MIC factor for the EOs of M. communist against bacteria is shown in Table 4. Essential oils MIC was 1.565\% for S. mutants whereas it was $3.125 \%$ against $S$. salivaris and $S$. sanguis. It shows that $S$. mutants was more susceptible to M. communis oil than the others.

Table 4. Minimal Inhibitory Concentration of Myrtle EOs

\begin{tabular}{lcc}
\hline Micro-Organisms & MIC, \%v/v & PTCC \\
\hline S. mutants & 1.565 & 1683 \\
S. Salivaris & 3.125 & 1448 \\
S. Sanguis & 3.125 & 1449 \\
\hline
\end{tabular}

Akin also searched about the antibacterial activity of the essential oils of Eucalyptus camaldulensis and Myrtus communis growing in Northern Cyprus. They reported that M. communis showed higher efficacy on Gram positive and Gram negative bacteria while E. camaldulensis was found to have a low activity (27). AlAnbori et al. found that the MIC of myrtle was $106.6 \mu \mathrm{g} / \mathrm{mL}$ compared to $3.3 \mu \mathrm{g} / \mathrm{mL}$ of chlorhexidine mouth rinse. They showed that the antibacterial effect of myrtle on Mutants of streptococci was due to its flavonoids content. Therefore, ethanolic extract of myrtle could be a potential remedy for the prevention of colonization by Mutants streptococci; thereby, preventing or hindering development of dental caries and single mouth rinse of myrtle extract could be significantly useful (28). Rasooli explained the antimicrobial effects of essential oils isolated from M. communis against nine different bacteria. They found that high monoterpenes hydrocarbons such as $\alpha$ - Pinene and Limonene contribute to the strong antimicrobial activity of $M$. communis (25). Previous studies and our in vitro results proved that EOs extracted from myrtle has an inhibitory effect on various bacteria like streptococcus. According to our results, the myrtle EOs inhibitory was the same as tetracycline for S. salivaris and S. mutants in high concentrations and $100 \%$ of EOs was even better than erythromycin in the case of S. sanguis. On the other hand, MIC test showed that $S$. mutants is very sensitive to low concentration of the myrtle EOs.

Therefore, myrtle EOs could be a potential remedy for the prevention and development of dental caries. Using the EOs in mouthwash or gum could be a good suggestion for future studies.

\subsection{Conclusions}

The results from the myrtle EOs showed a good antibacterial activity towards S. salivaris, S. canguis, and especially toward S. Mutants, which has been implicated in dental caries and plaque formation.

\section{Acknowledgments}

This work was financially supported by grant number EU-89248, from ice-chancellor for research affairs of Ahvaz Jundishapur University of Medical Sciences. This paper is issued from thesis of student Shervin Rasouli.

\section{References}

1. Asikainen S, Alaluusua S. Bacteriology of dental infections. Eur Heart J. 1993;14 Suppl K:43-50. [PubMed: 8131787].

2. Scannapieco FA, Cantos A. Oral inflammation and infection, and chronic medical diseases: implications for the elderly. Periodontol 2000. 2016;72(1):153-75. doi: 10.1111/prd.12129. [PubMed: 27501498].

3. Aleksic V, Mimica-Dukic N, Simin N, Nedeljkovic NS, Knezevic P. Synergistic effect of Myrtus communis L. essential oils and conventional antibiotics against multi-drug resistant Acinetobacter baumannii wound isolates. Phytomedicine. 2014;21(12):1666-74. doi: 10.1016/j.phymed.2014.08.013. [PubMed: 25442275].

4. Gortzi O, Lalas S, Chinou I, Tsaknis J. Reevaluation of antimicrobial and antioxidant activity of Thymus spp. extracts before and after encapsulation in liposomes. J Food Prot. 2006;69(12):2998-3005. [PubMed: 17186670].

5. Yap PS, Yiap BC, Ping HC, Lim SH. Essential oils, a new horizon in combating bacterial antibiotic resistance. Open Microbiol J. 2014;8:614. doi: 10.2174/1874285801408010006. [PubMed: 24627729]. [PubMed Central: PMC3950955]

6. Dagli N, Dagli R. Possible use of essential oils in dentistry. J Int Oral Health. 2014;6(3):i-ii. [PubMed: 25083049]. [PubMed Central: PMC4109163].

7. Sharifi-Rad J, Sureda A, Tenore GC, Daglia M, Sharifi-Rad M, Valussi M, et al. Biological Activities of Essential Oils: From Plant Chemoecology to Traditional Healing Systems. Molecules. 2017;22(1). doi: 10.3390/molecules22010070. [PubMed: 28045446].

8. Lewinsohn E, Gijzen M. Phytochemical diversity: The sounds of silent metabolism. Plant Sci. 2009;176(2):161-9. doi: 10.1016/j.plantsci.2008.09.018.

9. Freires IA, Denny C, Benso B, de Alencar SM, Rosalen PL. Antibacterial Activity of Essential Oils and Their Isolated Constituents against Cariogenic Bacteria: A Systematic Review. Molecules. 2015;20(4):7329-58. doi: 10.3390/molecules20047329. [PubMed: 25911964].

10. Russo R, Corasaniti MT, Bagetta G, Morrone LA. Exploitation of cytotoxicity of some essential oils for translation in cancer therapy. Evid Based Complement Alternat Med. 2015;2015:397821. doi: 10.1155/2015/397821. [PubMed: 25722735]. [PubMed Central: PMC4334976].

11. Hamedi A, Zarshenas MM, Sohrabpour M, Zargaran A. Herbal medicinal oils in traditional Persian medicine. Pharm Biol. 2013;51(9):1208-18. doi: 10.3109/13880209.2013.777462. [PubMed: 23746335].

12. Raisi Dehkordi Z, Hosseini Baharanchi FS, Bekhradi R. Effect of lavender inhalation on the symptoms of primary dysmenorrhea and the amount of menstrual bleeding: A randomized clinical trial. Complement Ther Med. 2014;22(2):212-9. doi: 10.1016/j.ctim.2013.12.011. [PubMed: 24731891].

13. Oboh G, Akinbola IA, Ademosun AO, Sanni DM, Odubanjo OV, Olasehinde TA, et al. Essential Oil from Clove Bud (Eugenia aromatica Kuntze) Inhibit Key Enzymes Relevant to the Management of Type-2 Diabetes and Some Pro-oxidant Induced Lipid Peroxidation in Rats Pancreas in vitro. J Oleo Sci. 2015;64(7):775-82. doi 10.5650/jos.ess14274. [PubMed: 25994557].

14. Russo A, Formisano C, Rigano D, Cardile V, Arnold NA, Senatore F. Comparative phytochemical profile and antiproliferative activity on human melanoma cells of essential oils of three lebanese Salvia species. Indust Crops Prod. 2016;83:492-9. doi: 10.1016/j.indcrop.2015.12.080. 
15. Russo R, Ciociaro A, Berliocchi L, Cassiano MG, Rombola L, Ragusa $S$, et al. Implication of limonene and linalyl acetate in cytotoxicity induced by bergamot essential oil in human neuroblastoma cells. Fitoterapia. 2013;89:48-57. doi: 10.1016/j.fitote.2013.05.014. [PubMed: 23707744].

16. Mekonnen A, Yitayew B, Tesema A, Taddese S. In Vitro Antimicrobial Activity of Essential Oil of Thymus schimperi, Matricaria chamomilla, Eucalyptus globulus, and Rosmarinus officinalis. Int J Microbiol. 2016;2016:9545693. doi: 10.1155/2016/9545693. [PubMed: 26880928]. [PubMed Central: PMC4736320].

17. Azzimonti B, Cochis A, Beyrouthy ME, Iriti M, Uberti F, Sorrentino $\mathrm{R}$, et al. Essential Oil from Berries of Lebanese Juniperus excelsa M. Bieb Displays Similar Antibacterial Activity to Chlorhexidine but Higher Cytocompatibility with Human Oral Primary Cells. Molecules. 2015;20(5):9344-57. doi: 10.3390/molecules20059344. [PubMed: 26007187].

18. Gardeli C, Vassiliki P, Athanasios M, Kibouris T, Komaitis M. Essential oil composition of Pistacia lentiscus L. and Myrtus communis L.: Evaluation of antioxidant capacity of methanolic extracts. Food Chemistry. 2008;107(3):1120-30. doi:10.1016/j.foodchem.2007.09.036.

19. Yadegarinia D, Gachkar L, Rezaei MB, Taghizadeh M, Astaneh SA, Rasooli I. Biochemical activities of Iranian Mentha piperita L. and Myrtus communis L. essential oils. Phytochemistry. 2006;67(12):1249-55. doi: 10.1016/j.phytochem.2006.04.025. [PubMed: 16777154].

20. Subramenium GA, Vijayakumar K, Pandian SK. Limonene inhibits streptococcal biofilm formation by targeting surfaceassociated virulence factors. J Med Microbiol. 2015;64(8):879-90. doi: 10.1099/jmm.0.000105. [PubMed: 26294065].

21. Mitrakul K, Srisatjaluk R, Srisukh V, Vongsawan K. Citrus hystrix (makrut oil) oral sprays inhibit Streptococcus mutans biofilm formation. Sci Asia. 2016;42(1):12. doi: 10.2306/scienceasia15131874.2016.42.012.

22. Baharvand-Ahmadi B, Bahmani M, Naghdi N, Saki K, BaharvandAhmadi S, Rafieian-Kopaei M. Review on phytochemistry, therapeutic and pharmacological effects of myrtus (Myrtus communis). Der Pharmacia Let. 2015;7(11):160-5.

23. Bailey WR, Scott EG. Diagnostic microbiology. Louis; 1970.

24. Berka-Zougali B, Ferhat MA, Hassani A, Chemat F, Allaf KS. Comparative study of essential oils extracted from Algerian Myrtus communis L. leaves using microwaves and hydrodistillation. Int J Mol Sci. 2012;13(4):4673-95. doi: 10.3390/ijms13044673. [PubMed: 22606003]. [PubMed Central: PMC3344239].

25. Rasooli I, Moosavi ML, Rezaee MB, Jaimand K. Susceptibility of microorganisms to Myrtus communis L. essential oil and its chemical composition. J Agric Sci Technol. 2010;4:127-33.

26. Rasooli I, Rezaei MB. Bioactivity and Chemical Properties of Essential Oils fromZataria multifloraBoiss andMentha longifolia(L.) Huds. J Essential Oil Res. 2002;14(2):141-6. doi: 10.1080/10412905.2002.9699800.

27. Akin M, Aktumsek A, Nostro A. Antibacterial activity and composition of the essential oils of Eucalyptus camaldulensis Dehn. and Myrtus communis L. growing in Northern Cyprus. Afr J Biotechnol. 2010;9(4).

28. AlAnbori DKA, AlNimer MSM, AlWeheb AM. Antibacterial activity of ethanolic extract of Myrtus communis. L leaves against salivary Mutans streptococci. Saudi Dent J. 2008;20(2):82-7. 